This is the authors accepted manuscript of an article published as the version of record in Nordic Social Work Research (C) Taylor \& Francis 2020 Informa UK Limited, trading as Taylor \& Francis Group, https://doi.org/10.1080/2156857X.2020.1838941

\title{
Safety and health challenges affecting the informal caregivers of children
}

Maria Lindholm ${ }^{\mathrm{a} *}$, A. Reiman ${ }^{\mathrm{a}}$ and M. Keväjärviab

${ }^{a}$ Industrial Engineering and Management, University of Oulu, Oulu, Finland; ${ }^{b}$ Oulu Vocational College, Oulu, Finland

*Maria Lindholm, P.O. Box 8000, FI-90014 University of Oulu, Oulu, Finland; Tel.: +35850 3505341. E-mail: maria.lindholm@ oulu.fi

Acknowledgements

This study was supported by The Foundation for Municipal Development sr. in Finland. 


\section{Safety and health challenges affecting the informal caregivers of children}

Informal caregiving of children with special needs is a complex entity with a mixture of different caregiving tasks performed on a regular basis. This study is focused on the perceptions of the safety and health challenges of the informal caregivers of children with special needs in Finland. An in-depth analysis was conducted on data collected from 25 qualitative interviews. The main safety and health challenges that emerged from the data analysis included issues with caregiving arrangements and related bureaucracy, anxiety because of the financial situation they are in, uncertainty on certain caregiving tasks and constant worry about the child's health. The informal caregivers are tired, endure children's aggressive behaviour and have physical discomfort and stress. Informal caregiving is discussed in the context of work system theory and recommendations for future studies are presented. The results indicated the need to understand better the challenges confronted in informal caregiving in order to develop practices, services and policies for the informal caregivers of children.

Keywords: health; human factors and ergonomics; informal caregiver of child; safety; work system

\section{Introduction}

Informal caregiving as a cost-efficient part of the social and health services is used broadly across nations to respond to the diverse need for care (Grady et al., 2014; Hiel et al., 2015). An informal caregiver is an individual, such as a family member, who provides unpaid care for a child or dependent adult with a chronic illness, disability, or other long lasting health or care need outside a professional framework (International Alliance of Carer Organisations 2018). The roles of informal caregivers differ depending on the condition of the person being cared for. Care can be defined in different ways, such as hours per week spent, types of activities performed, and duration of the care period (Care Alliance Ireland 2010; Glendinning et al. 2009). In Finland, where this study is conducted, informal care can be provided for elderly, disabled or sick person at home by relative or a close one, and informal caregiver is entitled to care allowance if the care is time-consuming and demanding (Finlex 2005). 
It has been estimated that in the European Union, there are approximately 100-125 million informal caregivers and that over three-quarters of long-term care is realised by relatives and close friends. In Finland, there are approximately 60,000 informal caregivers of which around 8400 are informal caregivers of children with special needs (Anderson et al. 2009; Central Association of Carers in Finland 2018; Mestheneos and Triantafillou 2005; THL 2020). In Europe, approximately $40 \%$ of informal caregivers are in employment. The informal caregivers can be entitled to care allowances, which is less than $30 \%$ of the average wage in many countries, and to use carer's leave from employment. The provision of the care allowance generally requires that caregiving is a fulltime activity, or nearly so. In addition to care allowances, informal caregivers may be provided carer services (Hoffmann and Rodrigues 2010; Huber, Rodrigues, et al. 2009; Martens 2018). In Finland, informal caregivers sign an informal care agreement with the care receiver's municipality of residence. The Ministry of Social Affairs and Health (2020) defined the minimum amount of the dependent care allowance as 408 euros per month. During a heavy transitional stage of care, the allowance is at least 816 euros per month which is roughly one third of the average wage level in Finland. In addition to support services, such as respite care, informal caregivers are also entitled to accident insurance (Hoffmann and Rodrigues 2010; Huber, Rodrigues, et al. 2009; OSF 2017).

An informal caregiver of a child with special needs is usually a parent providing informal care for her/his child. Children with special needs is a group with a wide range of diagnoses and functional limitations and an elevated need for continuous medical, nursing and therapeutic services. Neurodevelopmental disorders can be for example intellectual and developmental disability, autism spectrum disorders or cerebral palsy, while physical disabilities can be for example spinal cord injury, scoliosis or traumatic brain injury (Caicedo 2014; Law et al. 2004; Strickland et al. 2011; Thapar et al. 2017).

Previous studies have shown that caregiving affects the health of the informal caregiver of children. Informal caregivers of children with special needs have more physical and psychosocial 
health issues compared with non-caregivers and informal caregivers of children with special needs have greater odds of health problems compared to parents of healthy children (Berglund et al. 2015; Brehaut et al. 2009; Care Alliance Ireland 2008). Safety and health are interrelated elements of individual well-being. Even though well-being is realised at individual levels, it is affected by others, such as close relatives, the community and the nation. Furthermore, well-being, well-being at work and human productivity are linked (e.g. Reiman and Väyrynen 2018; Schulte and Vainio 2010). This synergistic duality also applies to informal caregivers because their well-being fosters their ability and satisfaction in performing their caring tasks. This study aims to contribute to this discussion by providing an in-depth analysis of the safety and health perceptions of informal caregivers of children in Finland. The study aims to answer the following research questions (RQ):

RQ1: What psychosocial and physical load factors do the informal caregivers of children experience?

RQ2: What safety and health issues do the informal caregivers of children encounter?

\section{Well-being of informal caregivers of children with special needs}

The informal caregivers of children with special needs have higher odds of reporting poorer health than the parents of children without disabilities (Brehaut et al. 2009). The informal caregivers of children report more often chronic conditions, activity limitations, psychological distress and elevated depressive symptoms than the parents of typically developing children (Brehaut et al. 2009; Yamaoka et al. 2016). Back and neck pain are common while some of the informal caregivers have been injured by children's impulsive or violent behaviour (Murphy et al. 2007). Furthermore, they may have long-term negative health consequences because of parenting a child with special needs (Smith and Grzywacz 2014). The informal caregivers of children often neglect their own health because of lack of time, inadequate resources for support, and low prioritisation of their own needs (Murphy et al., 2007). 
Informal caregivers' psychosocial and physical health is influenced for example by child's behaviour, caregiving demands and family function (Raina et al. 2005). The informal caregivers of children have fewer social contacts and less time for themselves. Kim et al. (2018) described that mother caregivers of children with special needs modified their leisure patterns in order to suit the desires and needs of the child. Murphy et al. (2007) describe that feelings of lack of control and being in a state of preparedness cause stress for the informal caregivers of children. They have to focus on the child all the time, do not have time for everyday tasks and worry about other family members and their other children because the informal care takes time from them.

Informal caregivers have anxiety about ensuring that the child receives all the services he/she is entitled to. Uncertainty of the future adds to the emotional stress: informal caregivers worry about their children and what will happen to them if the parent cannot continue to be an informal caregiver or if the children outlive the parents (Murphy et al., 2007). Moreover, the informal caregivers of children are likely to be economically disadvantaged and have higher needs for help in the household, both of which are related to higher health risks (Emerson 2003; Leinonen 2011; Vonneilich et al. 2016).

\section{Informal caregiving and work}

Even though informal caregiving is not considered as work, in Finland, the municipality has to insure the informal caregiver with an accident insurance as presented in Workers' Compensation Act. In the workers' compensation insurance, what is prescribed of an employee applies to the informal caregiver and what is prescribed of an employer applies to the municipality even though there is no employment relationship (Finlex 2005; Workers' Compensation Act 2015). This encourages to discuss informal caregiving in the context of human work. Human factors/ergonomics (HF/E) is a human-centric discipline that focus on human well-being and performance. HF/E facilitates discomfort factor and risk identification and design-oriented solution seeking processes (Dul et al. 
2012; Karwowski 2005). Work system theory as one traditional approach presented in the HF/E literature (see e.g. Smith and Carayon-Sainfort, 1989; Dul et al. 2012) provides a holistic framework to identifying and understanding individual level success factors, challenges, discomfort and load factors, conditions affecting performance and risks for accidents at work contexts. In its simplest form, a work system can be described as an entity that is formed when an individual performs his/her work tasks with different tools and technologies in a certain work environment. Despite the concept of work system is strongly associated to work it can be utilized to describe non-work contexts; like individuals as product users or persons receiving services (Dul et al. 2012). As described by Carayon and Smith (2000), work systems should strive for a balance, i.e. the challenges, load factors and risks related to work environments, tools and technologies, work tasks and organisational context should be identified and managed, to achieve individual level well-being and productivity. Based on the balanced work system theory (e.g. Carayon 2006, 2009; Karwowski 2005; Väyrynen et al. 2016), work systems - if not in a balance - can lead to adverse safety and health outputs like physiological and psychological stress, accidents and injuries and quality errors and losses.

\section{Methods and material}

\section{Study design}

Prior this interview study, in 2017 a web-based survey through a Facebook channel was conducted for informal caregivers to provide an overview of the challenges faced by the informal caregivers in Finland. Altogether 154 responses were received (of approximately 2000 Facebook channel followers). From those, 84 responses focused on informal caregiving of children. Based on the survey informal caregivers of children emphasised tiredness, insecure or unsafe feelings, child's health and behaviour and self-health issues (Authors, 2017).

To facilitate more in-depth understanding of the challenges informal caregivers of children face, a qualitative interview study was conducted using a semi-structured interview form with pre- 
prepared topics on daily tasks concerning caregiving, challenges confronted, services provided, and finally on their own experiences of health and well-being. However, room for other emerging topics were left in the interviews as instructed by for instance Gideon (2012). Pre-prepared topics focused on challenges confronted while providing informal caregiving, what kind of support services they are provided and how the interviewees' see their own health and well-being in general. At the end of the interview, the researcher made an overview of the discussion and provided the respondents and opportunity to add or correct their responses.

\section{Data collection methods}

The request to participate in the interviews was sent in a newsletter and through the Facebook by Informal Caregivers of the Oulu region, a local society that supports informal caregivers, and by Lioness mothers, a national association that offers peer support to the parents of children with special needs. Both are voluntary organisations. The Informal Caregivers of the Oulu region has about 470 members, eight employees and 1200 followers in Facebook. The Lioness mothers has 1900 members, seven employees and 7100 followers in Facebook. The willing participants contacted directly the researcher by e-mail. For this study, as an inclusion criteria researched used the following: (1) parents over 18 years of age, (2) able to communicate in Finnish, and (3) having at least one child with special needs. The diagnosis of the child was not decisive; both physical and mental disabilities were acceptable. All the participants signed an informed consent form, which explained that their participation was voluntary and that they could withdraw from the study at any time. The form included information about the research concerns, what was expected from participants and what the researchers would do with the material. The interviews were conducted in Northern, Western and Southern Finland in the autumn 2017 and winter of 2018. A total of 25 caregivers were interviewed. The interviews were conducted in the participants' homes or in offices. The interviews were recorded and transcribed by the researcher. 


\section{Material}

The interviews took 82 minutes (16 SD) on average, and the transcriptions resulted in 124 pages. Of the respondents, 24 were women and 1 was a man. Of the respondents, 15 were from Northern Finland, 6 were from Southern Finland and 4 were from Western Finland. Of the informal caregivers, 3 had two children with special needs. Table 1 presents the distribution of the ages and employment of the informal caregivers, type of informal care and the distribution of the ages of the children with special needs.

Table 1. Distribution of ages, employment and type of care by the informal caregivers and the distribution of the ages of the children with special needs

\section{Data analysis}

The interviews were transcribed and analysed using NVivo 11 by applying the open-coding analysis approach (see Flick 2009; Strauss and Corbin 1998) in order to identify the safety and health challenges experienced by the informal caregivers of children with special needs. During the analysis, one researcher first read all the transcriptions and noted different challenges confronted that arose from the answers. Next, the researcher divided these into psychosocial and physical load factors and other safety and health issues encountered. On the third round, the researchers categorized the findings into six larger entities representing the challenges confronted in informal caregiving. In addition, the safety and health issues encountered in informal caregiving were categorised. The categorisations followed the premises of open coding, i.e. written data is conceptualised into separate categories and given a name that represents or stands for it (Strauss \& Corbin 1998). 


\section{Findings}

\section{Identified challenges (RQ1)}

Each interview was analysed separately and certain themes were identified to describe the psychosocial and physical load factors encountered. Six main themes arose from the interviews as follows: Services and bureaucracy, Financial situation, Balancing between informal care, work, leisure time and social life, Informal care tasks, Worries about or because of the child, and Indiscreet behaviour. The variety of the themes is broad including macro level (first three themes) contexts like organisation and management of the caregiving as well as micro level challenges that can be situated into the environments where caregiving is carried out and actual caregiving processes in practice. To emphasise the total burden and stress experienced, at the end of the interviews, some respondents recommended against being an informal caregiver, like highlighted in an interview quotation by informal caregiver 10 who had been an informal caregiver for under five years of a child with neurodevelopmental disorder:

"Do not be an informal caregiver. You don't get paid and you lose your mind and life". Categorised challenges with exemplary citations are presented in an order from macro level to micro level in the chapters below.

\section{Services and bureaucracy}

Challenges related to bureaucracy and services received were highlighted in every interview when asked about the services needed for informal caregiving. The interviewees felt that the authorities did not give them enough information, and they had to be extremely proactive in searching for information, sending applications and filing appeals in response to negative decisions. Admitted services might be unsuitable or insufficient considering that the child's disorders were incurable, and it was difficult to obtain enough assistive devices. Transitional stages were challenging, the customer service persons changed often, and the handling times were long. For example, informal caregiver 12 
who had been an informal caregiver for almost five years of a child with neurodevelopmental disorder received the dependent care allowance after an 11-month wait and an appeal, and informal caregiver 10 stated that it is exhausting to be in contact with multiple service providers and apply for the services when you have to argue why the child needs the services he/she is entitled to have and said,

"When the child received the diagnosis, I thought we would get support and help. I feel like you won't get anything if you don't fight about it."

The insufficiency and inactivity of the available support services caused challenges in integrating informal caregiving with personal lives. If the child is deemed as behaving difficultly by the service provider's employee, the additional home care service may require that the parent is at home while home care service is provided. This diminishes the benefit of the additional service to the informal caregiver. The informal caregivers often felt uncared for, unheard or misunderstood. For example, informal caregiver 13 who had been an informal caregiver for almost five years felt the need for more help and asked for an additional home-help service for 12 hours per month. The informal caregiver 13 was denied the service, resulting in personal health challenges. As a consequence, the child had to move temporarily to the other parent's home. When informal caregiver 13 was again the informal caregiver, home-help service for 56 hours per month was granted. Hence, the costs would have been less if the service providers had listened to the informal caregiver sooner than they did.

The informal caregivers also felt that some bureaucratic processes were unnecessary. For example, informal caregiver 4 who had been an informal caregiver for almost five years needed authorisation from a child, who was around five years old and with physical disabilities, in order to use service vouchers for informal caregiver's leave. Almost all of the informal caregivers felt insecure and even unsafe because of the lack of support, lack of advice and lack of services. Most of the informal caregivers felt that they did not have enough help, and a few of them had to report 
themselves to the child welfare inspector to obtain services. Furthermore, two of the informal caregivers became targets of a child welfare investigation because of misunderstandings. Informal caregiver 17 who had been an informal caregiver under five years of a child with physical disability had even hired a lawyer who specialised in services for the disabled.

\section{Financial situation}

During the interviews, most of the interviewees described their worries about finances and the ability to meet all the expenses. Less than half of the informal caregivers had feelings of insecurity and uncertainty because of their financial situation, and they were anxious about the dependent care allowance and its amount. Informal caregiver 5 who had been an informal caregiver of a child with physical disabilities for under ten years described that as an informal caregiver of a child you do not fit in any category. The pressure leads you to be and informal caregiver which is a very weak position financially. The informal caregiver 5 mentioned that

"It's a challenging situation in society to be an informal caregiver and unemployed."

The informal caregivers who were unemployed, single and did not have a spouse to help with the finances or had more than one child were particularly stressed. However, a few informal caregivers who were married felt unequal because of their dependency on their husbands.

Some informal caregivers also worried about their future as senior citizens because of their low pension accrual. If an informal caregiver is unemployed, the only pension accrual is from the small dependent care allowance. Informal caregiver 2 felt that because it is not possible to work while being an informal caregiver and because of the low dependent care allowance and low pension accrual, informal caregiving is causing poverty:

"Informal caregiving leads to poverty now and in old age." 
Overall, the informal caregivers were dissatisfied, and they felt that the amount of dependent care allowance was unfair considering that the monthly cost of the child's institutional care would cost the society a great deal more than they currently received.

\section{Balancing between informal care, work, leisure time and social life}

During the interviews, the informal caregivers described the challenges in balancing the informal caregiving with other aspects of their lives. Almost half of them felt that they have had to give up many aspects of their lives because of the informal caregiving, and they felt somewhat bitter. Informal caregiving can be entirely consuming, as the informal caregiver 10 said,

"There is no life. I used to work but I had to quit. I left all my hobbies too since I simply didn't have the energy."

Most of the informal caregivers did not have the time nor the energy for a social life or regular employment, and they did not have enough money for hobbies. They described that they were withdrawn from the outside world and excluded from their working lives without their consent. Informal caregiver 2 who had been an informal caregiver around ten years of two children with neurodevelopmental disorder described the feelings that arise when informal caregiving takes everything away, and said,

\section{"Informal caregiving is an exclusion trap, it breaks your career."}

Most of those who were employed admitted that informal caregiving affected their work. Overall, the informal caregivers described that they had to prioritise what they had time to do, and household chores were usually neglected. They also felt that the lack of energy negatively affected their relationship with their spouse. Furthermore, almost half of the informal caregivers often had feelings of guilt and inadequacy. They felt guilty if they took time for themselves or because their other children may have had less attention than the disabled child, and they were worried that their caregiving was inadequate. 


\section{Informal care tasks}

When asked about the informal care tasks, most of interviewees described the burden and exhaustion they felt because of the informal caregiving. Their workload can be understood by thinking about the number of personal assistants the child may need: the school day may require from one to three assistants; and the taxi ride from school to home alone may require two assistants. The caregiving was particularly challenging if the child needed constant physical care and the informal caregiver had to wake up several times during the night. Moreover, their working positions were non-ergonomic because they did not have proper care equipment, and the home environment was not designed for the care they had to provide.

Most of the informal caregivers expressed that caregiving was psychosocially tiring because they did the same things repeatedly. Their time was completely consumed by managing all the child's requirements, such as kindergarten or school, doctors, therapists, rehabilitation and caregiving at home in addition to performing daily chores. Informal caregiver 13 described how it is impossible to leave the child alone at all, and said,

"The biggest challenge is that you have to be with the boy all the time. I take the child even to the toilet with me."

The previous comment describes the constant attention the children need. Informal caregiving is something you cannot do with normal working hours. Instead, you need to stay focused on the child all the time.

\section{Worries about or because of the child}

The child was often the object of fears and worries or was actually causing them. The informal caregivers worried about the health of the child, the quality of their care and of temporary care facilities as well as what would happen to the child in the future. Overall, the informal caregivers 
often felt helpless and insecure regarding their child's health and quality of care. Because of these worries, a few informal caregivers carried a first-aid kit everywhere, and they checked the locations of the nearest hospitals when they planned trips.

Some of the informal caregivers had worried because of the child's behaviour. Some of the children had a habit of running away without understanding the environment or had suicidal thoughts. Furthermore, the child's behaviour could be threatening to the child's siblings or to the informal caregiver. Such behaviour could be limited to breaking things, but it could also be directed at people. Informal caregiver 23 who had been an informal caregiver for under ten years of a child with neurodevelopmental disorder told that as a parent and informal caregiver, you are often the closest one and alone with the child, and the receiving end of the child's anger. Because the child is already too strong to handle alone, informal caregiver 23 must withdraw from threatening situations, as the following comment reveals,

"Well, I run out to escape. When the child was smaller, I could take and calm, and bind and hold on the child. But now I have to escape, I can't manage anymore."

The previous example emphasises the evolving nature of the challenges faced in informal caregiving. A few of the caregivers wondered how they will manage when the child grows and becomes more powerful.

\section{Indiscreet behaviour}

The informal caregivers often felt vulnerable because of worries about the disabled child's health. Hence, the tone of voice, word choices and behaviour had a great effect on how they felt they were treated. Informal caregiver 12 described that it felt like everything you do is either way wrong when discussing with service providers and authorities and said that

“I always feel like I'm doing something bad, that I'm the guilty one and doing something wrong. " 
A few of the informal caregivers recognised that the comments were not always meant to be improper but instead based on ignorance or thoughtless comments. However, most of the informal caregivers felt that they had encountered indiscreet behaviour. For example, before the child was correctly diagnosed, a doctor who had seen the child only for a short time decided that the parents did not love the child enough and that they were the reason for the child's behaviour. Hence, informal caregiver 25 left the meeting embarrassed. Overall, the informal caregivers felt undervalued by society as informal caregiver 16 who had been an informal caregiver under ten years of a child with neurodevelopmental disorder described the attitudes toward informal caregivers of children,

"I feel like second class citizen. -- If you're an informal caregiver of a child, people who don't understand anything about special children, they think that you're lazy or there is something else wrong with the parent."

Similarly, informal caregiver 12 described the feelings that most of the informal caregivers had. The quotation shows how the society sees the informal caregiving,

"I feel that it's work, even though it's my life. Society needs to see this as work, I'm not chilling at home. Others think that you can just be alone at home all day long. Still, you can't define if it's interaction (between mother and child) or work. For me, it's both constantly."

Overall, the informal caregivers had encountered understatement, criticism and harsh comments by authorities, teachers, service providers, doctors and relatives. Few of the interviewees described how they have toughened themselves but some days the comments, stares and long looks still hurt.

\section{Safety and health issues encountered by the informal caregivers (RQ2)}

Three themes, Tiredness, Physical discomfort, pain and stress, and Injuries caused by the child's behaviour, were identified as safety and health issues the caregivers had constantly encountered. The interviewees felt that the broad spectrum of the challenges confronted in informal caregiving have 
affected their vitality, and they have experienced physical injuries and extreme stress because of the child's behaviour. The informal caregivers considered themselves tired and were worried about their health now and in the future if their health would collapse. They also hoped for better health services, akin to occupational health services. Overall, they felt that they were in bad physical shape and that their psychosocial health was poor. As an example, the informal caregiver 13 had not received enough support and services to help with the burden which led to feelings of hopeless and wondering about how long it is possible to survive as an informal caregiver. As a sign of overload confronted, informal caregiver 13 said

"I have had a complete breakdown. The child had to spent two weeks with the other parent, I didn't see the child at all, I was completely worn out."

As an ultimate sign of overload, two of the informal caregivers had even had thoughts about suicide. Categorised challenges with exemplary citations are presented in the chapters below.

\section{Tiredness}

It cannot be addressed directly whether the tiredness informal caregivers experienced was physical or psychosocial tiredness but the answers indicate that it was both. Most of the informal caregivers described that their level of tiredness was seasonal and depended on the child's condition. For example, waking up several times every night could last from weeks to months, but for a few it was the norm and had lasted for years. Some of the informal caregivers described that they had felt extreme exhaustion and had needed lengthy sick leaves. Some of the informal caregivers had been diagnosed with depression. The tiredness was related to mood swings from irritability to anxiety and indifference, which affected the informal caregivers' personal well-being as well as their relationships and well-being with families and friends. However, no matter of the level of tiredness, the informal caregivers push forward: 
"When it is about your own child, there is no other choice. You have to try to hang on as long as possible",

explained informal caregiver 2. This reflects the moral obligations of parenting to take care of and raise your child.

At times, the tiredness had impaired the informal caregivers. Few times the tiredness had affected informal caregiving. Some of the informal caregivers had problems in everyday life because of their tiredness. Their memory had weakened, they were forgetful at work and home, and they felt absent-minded. For example, informal caregiver 6 who had been an informal caregiver for almost ten years of a child with neurodevelopmental disorder said that memory gaps had occurred while driving a car. Furthermore, the informal caregiver 8 who had been an informal caregiver under five years of a child with physical disabilities described the feelings,

"I'm almost always in low spirits, there is no colour in world. I don't recognise myself so much anymore."

Overall, the informal caregivers felt tired and downhearted. The view on life was covered with excessive negative thoughts.

\section{Physical discomfort, pain and stress}

The informal caregivers had experienced physical discomfort and pain in several body parts. Most often they located these into back and neck. The back pain was described mainly in lower back and both as sudden and long-lasting pain. The back and neck pain were caused by lifting and carrying the child, the child's abrupt movements, non-ergonomic working positions, and the constant tension they felt in their body. Informal caregiver 7 who had been an informal caregiver under five years of a child with physical disabilities told that more information about how to utilise child's and informal caregiver's own body weight when moving the child is needed. In addition to above mentioned, few of the informal caregivers had leg and hand pains, headaches and migraine, and overweight. Overall, 
the interviewees emphasised how they considered themselves being in a constant state of stress and readiness, as described by the informal caregiver 7 .

"This amount of stress does not feel healthy, and dizzy feelings hit when alarm clock alerts me after 3 at night to turn the child (in bed),"

A few of the interviewees had even had panic attacks. These symptoms were related to tiredness because the stress and constant worry caused sleeplessness. The stress was caused by dealing with multiple service providers and authorities, filling and sending applications over and over again, constant worrying about child's health, worrying how to hang on and financial situation.

\section{Injuries caused by the child's behaviour}

The informal caregivers had been injured by the child's behaviour. For example, the children had punched, kicked and bitten the informal caregivers, or they had thrown things at them. Bruises were ordinary occurrences, and a few had had broken bones, such as a nose or fingers. The informal caregivers described these injuries as normal every day occurrences, as informal caregiver 10 said,

“You get that punch or bite or scratch or throwed things. It's so commonplace for me, it's pretty normal for us."

The children usually did not hurt the informal caregivers on purpose. The behaviour was caused by other factors, such as autism, anxiety, the inability to express themselves or the inability to understand what was happening. However, a few of the informal caregivers had been directly targeted, and they felt unsafe because of the child's behaviour. A few of the informal caregivers also described that it felt unfair and psychosocially difficult to receive pain as a reward for trying to help the child. 


\section{Discussion}

Even though Nordic welfare states are often considered as "good examples" based on their social structures and policies, like for instance Leitner and Wroblewski (2006) bring out, this study showed that Finland has not been able to fully answer to the challenges regarding informal care of children. In this study, informal caregivers' safety and health challenges were under examination. A majority of the interviewees emphasised bureaucracy and services received, balancing between informal care and other life, and worries of the child as load factors challenging informal caregiving. The caregivers interviewed had felt insecurity and downheartedness. In addition, they were tired, worried about their health, and had physical health problems. All in all, the interviewees considered themselves stressful. From the health and well-being perspective it should be acknowledged that stress, as described for instance by Glendon and Clarke (2016), is associated to various health challenges like muscular tension, tiredness, headache, backache, depressive symptoms and the inability to maintain personal relationships. It should also be considered as Muscara et al. (2017) have brought out that in addition to having prolonged stress, as some of the respondents in this study had, parents can have acute stress reactions when the child has a life-threatening injury or illness.

A challenging question related to informal caregiving is; where the borderline between normal parenting and informal caregiving is, or is there such a borderline at all. This reflects the moral obligations of parenting to take care of and raise your child. Willingness is often linked to volunteering but parents cannot exactly volunteer to raise their children, it is an assumption that they do so. Overgaard (2019) suggests that instead of volunteering we should investigate the boundaries between formal-informal and paid-unpaid work. Again, it is difficult to determine when does the informal and unpaid work, i.e. parenting, stop and when a parent as an informal caregiver performs the same tasks that a professional caregiver would do if tasked to tend the child at the child's home, i.e. formal and paid work tasks. Furthermore, the parent cannot be forced to be an informal caregiver for her/his child, as shown in the Finnish Supreme Court's decisions where the municipality is 
obligated to organise the care and supported accommodation at home with other means if the parent is not informal caregiver or do not want to apply to be one (KHO 2005, 2007). In that case, the municipality must organise a hired employee to perform the tasks that the parent would have done as an informal caregiver. Finally, in Finland, the informal caregiver signs an informal care agreement with the care receiver's municipality of residence. Regarding workers' compensation insurance, employee and employer status are applied to the informal caregiver and to municipality (Finlex 2005; Workers' Compensation Act 2015).

\section{Informal caregiving of children in the work system context}

Even though informal caregiving is not considered work according to current labour laws, it still contains aspects that are associated with work as shown previously. It is also recognised in the HF/E literature that people who are not employed still perform work, as "the term work ... refer[s] to any form of human effort or activity, including recreation and leisure pursuits" (Hendrick 2002). When considering the informal caregivers in the light of the International Labour Organisation's 2030 Agenda for Sustainable Development (ILO 2017) that includes themes such as decent work, good health and well-being, gender equality and reduced inequality and ethical behaviour, it can be said that much needs to be done in order to help improve the labour rights of informal caregivers.

This dilemma between informal caregiving and the concept of work encouraged us, as researchers, to discuss the safety and health aspects of informal caregiving in the work system framework. Work systems, in a work context contain an element of organisational support, that is needed to perform the tasks required with certain tools and technologies at certain work environments. In the context of informal caregiving the element of organisational support is not so easily defined. For instance, municipalities and social and health care services could be referred to stakeholders providing organisational support in this context. However, as the informal caregivers sign an informal care agreement with the care receiver's municipality of residence in Finland, and in 
the accident insurance the informal caregiver is viewed as an employee and the municipality as an employer even though there is no employment relationship, we see that the municipality is the main organisation for informal caregivers in Finland. Based on the interviews, informal caregivers are often left without proper organisational support in this context. As informal caregivers seem to be on their own in their work systems, they need individual resilience to adapt and recover when encountering different challenges.

When informal caregiving is adapted through the work system framework, home should be considered as the main work environment and the tools and technologies required to perform informal caregiving tasks are those located in the home environments. A crucial question is whether these environments and the tools and technologies utilized are actually designed for such purposes where caring work is performed outside normal social and health care facilities. Another crucial question is how their purchasing and maintenance processes are managed and following risk management responsibilities defined.

Finally, the tasks required for informal caregiving should be discussed in the work system context. Informal caregiving includes a wide range of tasks that are physically and emotionally exhausting as brought out in this study. An important question is whether and how the informal caregivers are supported and guided to perform these tasks. As Verbeek et al. (2011) have shown, having effective long-term behaviour changes in work performance requires strong organisational support; here the municipalities must ensure that informal caregivers actually have possibilities to perform their work safely in practice. Such a support should not be limited to physical work tasks. For instance Collins et al. (2016) and Cachia et al. (2016) have emphasised the need to strengthen emotional support services to improve informal caregiving.

Based on this study there is a need for proactive measures to secure the safety and health of informal caregivers. To move forward to proactivity and fostering abilities to succeed under varying conditions, the balanced work system theory used in HF/E guides towards a holistic and proactive 
risk and load factor identification and management process. As pointed out in Figure 1 we emphasise the need to go in-depth into the root causes of the challenges identified to facilitate long-lasting improvements in informal caregiving.

Figure 1. Unbalanced work system and ideas for balanced work systems regarding informal caregivers

\section{Future research}

Based on this study, the problems encountered in dealing with bureaucracy and obtaining services caused many challenges in everyday life. Many of the interviewed informal caregivers had experienced situations in which they needed more help in order to recover, but they were not satisfied with the services they received. This is supported by Olin and Dunér (2016) who stated that social services are burdensome and by Särkikangas (2017) who described how families with children with special needs have to use tens of services, and how the parents typically have to supervise the professionals and even advise them. It is clear that the processes need to be faster and more fluent than they are. The dependent care allowances and the pension accrual are small, and they may not be adequate if the informal caregiver of children has to remain unemployed. The differences between informal caregivers of children and the retired elderly should be considered, and services that are specific to both should be offered. Future research should focus on determining which kind of help, training and strategies are most suitable in different situations.

The informal care of the elderly reduces the annual expenditures in public care in Finland by approximately 2.8 billion euros (Kehusmaa et al. 2013). Future research should be aimed to determine the amount by which the informal care of children reduces the annual expenditures on public care and taken into considerations regarding dependent care allowances. Furthermore, future research should be aimed to investigate the costs of informal caregivers' poor physical and 
psychological health to society and public care and to consider how much proactive measures would reduce these costs.

As Raina et al. (2005) suggested, providing informal caregivers with cognitive and behavioural strategies to manage the child's behaviour may be helpful. The need for these kinds of strategies is supported by this study since some the informal caregivers felt threatened by the child. Violence has been studied in home care and in other healthcare settings and it has been noted that it is associated with more work burnout, stress, depression and sleep problems. Future research should look for possible similar associations with informal caregivers and determine which of the existing protective factors, such as personal protective equipment and staffing, and strategies are usable for informal caregivers as well to protect them and decrease the feeling of unsafety (Baby et al., 2014; Farrell et al., 2014; Hanson et al., 2015). Regarding safety and health, it should also be discussed how the child views the informal care and formal care and what safety and health issues the child has in informal care.

Finally, future research should discuss informal caregiving from the perspective of work. As presented earlier, it is difficult to determine to what extent caring for your child can feel like work and when does the parenting stop. Because as an informal caregiver the parent performs the same tasks as a professional would perform while taking care of the child, it is also difficult to determine the differences from formal-informal and paid-unpaid work. This should be further discussed. However, as briefly discussed earlier in this study, informal caregiving can be considered with frameworks familiar with traditional occupational aspects such as balanced work system which can help acquiring holistic understanding of the elements that the person faces while acting inside his or her work system (Dul et al. 2012; Reiman and Väyrynen 2018). Similarly, other aspects and frameworks of work should be reviewed, and special attention needs to be aimed on health care and what can be transferred to informal caregiving. The important questions concern how to support informal caregivers properly and how to improve their individual resilience. How can informal 
caregivers maintain the three key elements of resilience, which Hollnagel et al. (2006) described as foresight, coping and recovery, in their unbalanced work systems?

\section{Limitations}

The limitations of qualitative interviews include a limited number of respondents and an overly homogenous study sample. There may also be a selection bias in selecting the respondents. Because this study was based on voluntariness, it cannot be determined how well the participants present the informal caregivers of children. The willing participant may be more active and willing to share their life than others. However, in the present study, the informal caregivers of children had different sociodemographic backgrounds, and they came from different geographic areas. Moreover, they had been informal caregivers for different lengths of time, and they cared for children who required different kinds of care. Saturation was reached because the same issues started to appear in the respondents' answers. This finding supported the view that this study had a satisfactory number of interviews. The interviews' analyses were conducted by only one researcher which may affect the interpretation of results. The findings were discussed with other researchers, and changes were made when necessary.

Poor word choices, too complex questions or questions that guide the respondents to answer in a certain way may have an effect on the results. Furthermore, the interaction between the researcher and the interviewee can affect to the interview's progress. The interviewee may not feel comfortable, or in their discussion, the interviewee and the researcher could be side-tracked from the purpose of the interview (Gideon 2012). In this study, these possibilities were considered before the interviews were conducted. Because the interviews were semi-structured, the researcher ensured that the important themes were discussed, but room was left for spontaneous discussion. When analysing the transcripts from the interviews, feelings and emphasised sentences or words may be omitted and 
important aspects unheeded. In this study, descriptions of non-verbal behaviours (crying) and action (looking at an object in the interview context) were included in the transcript.

Using work related frameworks while discussing the informal caregiving of children presents some challenges. It is difficult to determine when the parenting stops and when informal care begins, and what safety and health challenges are caused by parenting and what by informal caregiving. However, the environment, load factors, and so on can be discussed through the main principles of a balanced work system as factors affecting the individual.

\section{Conclusion}

Challenges related to services and bureaucracy and balancing between informal care and other life were identified affecting the informal caregivers of children with special needs. Furthermore, the informal caregivers are anxious because of the financial situation they are in, and they carry out burdensome tasks, worry because of the children, and face indiscreet behaviour. They are tired, have physical discomfort, pain and stress, and endure children's aggressive behaviour. All in all, informal caregivers interviewed felt that they did not have enough time or resources to take care of their own well-being, nor did they have proper health care. The results of this study demonstrate that informal caregivers are not equal to others in health or income and provide important knowledge for policy makers.

When considering informal caregiving through the work system framework, different analogies between informal caregiving and work can be identified even though it is difficult to separate parenting and informal care tasks. Work environments (mainly home), tasks (informal care), tools (tools and technologies required to perform informal caregiving tasks), organisational support (from the municipalities and social and health care services), and employee's (informal caregiver) own skills and individual resilience all need to be understood better and improved accordingly to ensure balanced and productive informal care. 
Acknowledgements

This study was supported by The Foundation for Municipal Development sr. in Finland.

\section{References}

Authors, 2017

Anderson, R., Mikuliç, B., Vermeylen, G., Lyly-Yrjanainen, M. and Zigante, V. (2009), Second European Quality of Life Survey - Overview, European Foundation for the Improvement of Living and Working Conditions, Luxembourg: Office for Official Publications of the European Communities, available at:https://doi.org/ISBN 978-92-897-0847-0.

Baby, M., Glue, P. and Carlyle, D. (2014), "'Violence is Not Part of Our Job': A Thematic Analysis of Psychiatric Mental Health Nurses' Experiences of Patient Assaults from a New Zealand Perspective", Issues in Mental Health Nursing, Vol. 35 No. 9, pp. 647-655.

Berglund, E., Lytsy, P. and Westerling, R. (2015), "Health and wellbeing in informal caregivers and noncaregivers: A comparative cross-sectional study of the Swedish a general population", Health and Quality of Life Outcomes, Health and Quality of Life Outcomes, Vol. 13 No. 109, pp. 1-11.

Brehaut, J.C., Kohen, D.E., Garner, R.E., Miller, A.R., Lach, L.M., Klassen, A.F. and Rosenbaum, P.L. (2009), "Health Among Caregivers of Children With Health Problems: Findings From a Canadian Population-Based Study", Am J Public Health, Vol. 99 No. 7, pp. 1254-1262.

Cachia, R.L., Anderson, A. and Moore, D.W. (2016), "Mindfulness, Stress and Well-Being in Parents of Children with Autism Spectrum Disorder: A Systematic Review", Journal of Child and Family Studies, Springer US, Vol. 25 No. 1, pp. 1-14.

Caicedo, C. (2014), "Families with special needs children: family health, functioning, and care burden.", $J$ Am Psychiatr Nurses Assoc., Vol. 20 No. 6, pp. 398-407.

Carayon, P. (2006), "Human Factors of Complex Sociotechnical Systems", Applied Ergonomics, Vol. 37 No. 4, pp. 525-535.

Carayon, P. (2009), "The Balance Theory and the Work System Model ... Twenty Years Later", International Journal of Human-Computer Interaction, Vol. 25 No. 5, pp. 313-327.

Carayon and Smith. (2000). Work organization and ergonomics. Applied ergonomics, Vol. 31 No. 6, pp. 649662.

Care Alliance Ireland. (2008), "Health and Wellbeing of Family Carers in Ireland: Results of a survey of recipients of the Carer's Allowance", Care Alliance Ireland, Dublin, available at: http://www.carealliance.ie/userfiles/file/CareAllianceIrelandHealthandWellbeingofFamilyCarersNov200 8.pdf.

Care Alliance Ireland. (2010), Family Caring in Ireland, Dublin, available at: http://www.carealliance.ie/userfiles/file/Family Caring in IrelandAugust2010.pdf.

Central Association of Carers in Finland. (2018), "Carers Finland", available at: https://omaishoitajat.fi/carersfinland/.

Collins, A., Hennessy-Anderson, N., Hosking, S., Hynson, J., Remedios, C. and Thomas, K. (2016), "Lived experiences of parents caring for a child with a life-limiting condition in Australia: A qualitative study", Palliative Medicine, Vol. 30 No. 10, pp. 950-959.

Dul, J., Bruder, R., Buckle, P., Carayon, P., Falzon, P., Marras, W., Wilson, J., et al. (2012), “A strategy for human factors/ergonomics: Developing the discipline and profession”, Ergonomics, Vol. 55 No. 4, pp. 377-395.

Emerson, E. (2003), "Mothers of children and adolescents with intellectual disability: social and economic situation, mental health status, and the self-assessed social and psychological impact of the child's difficultie", Journal of Intellectual Disability Research, Vol. 47 No. 4, pp. 385-399. 
Farrell, G.A., Shafiei, T. and Chan, S.P. (2014), "Patient and visitor assault on nurses and midwives: An exploratory study of employer 'protective' factors", International Journal of Mental Health Nursing, Vol. 23 No. 1, pp. 88-96.

Flick, U. (2009), An Introduction to Qualitative Research, 4th ed., SAGE Publications, London.

Finlex. (2005), "Laki omaishoidon tuesta 937/2005 (Act on Support for Informal Care)", available at: http://www.finlex.fi/fi/laki/ajantasa/2005/20050937 (accessed 19 February 2018).

Gideon, L. (2012), Handbook of Survey Methodology for the Social Sciences, Springer Science+Business Media, New York.

Glendinning, C., Tjadens, F., Arksey, H., Moree, M., Moran, N. and Nies, H. (2009), Care Provision within Families and Its Socio-Economic Impact on Care Providers, York Social Policy Unit, Social Policy Research Unit, University of York, available at: http://eprints.whiterose.ac.uk/73507/.

Glendon, A.I. and Clarke, S.G. (2016), Human Safety and Risk Management. A Psychological Perspective, 3rd ed., CRC Press, Boca Raton, FL.

Grady, P.A., Gullatte, M. and Rosenbaum, L.M. (2014), "The 2014 national nursing research roundtable: The science of caregiving", Nursing Outlook, Elsevier Ltd, Vol. 62 No. 5, pp. 362-365.

Hanson, G.C., Perrin, N.A., Moss, H., Laharnar, N. and Glass, N. (2015), "Workplace violence against homecare workers and its relationship with workers health outcomes: A cross-sectional study", $B M C$ Public Health, Vol. 15 No. 11, pp. 1-13.

Hendrick, H.W. (2002), "An Overview of Macroergonomics”, in Hendrick, H.W. and Kleiner, B.M. (Eds.), Macroergonomics: Theory, Methods and Applications, Mahwah, NJ: Lawrence Erlbaum Associates, pp. $1-23$.

Hiel, L., Beenackers, M.A., Renders, C.M., Robroek, S.J.W., Burdorf, A. and Croezen, S. (2015), "Providing personal informal care to older European adults: Should we care about the caregivers' health?", Preventive Medicine, Elsevier Inc., Vol. 70, pp. 64-68.

Hoffmann, F. and Rodrigues, R. (2010), Informal Carers: Who Takes Care of Them?, Policy Brief, Vol. April, European Centre for Social Welfare Policy and Research, Vienna, available at: http://citeseerx.ist.psu.edu/viewdoc/download?doi=10.1.1.627.6793\&rep=rep1\&type=pdf.

Hollnagel, E., Woods, D.D. and Leveson, N.C. (2006), Resilience Engineering: Concepts and Precepts, Aldershot, UK: Ashgate.

Huber, M., Rodrigues, R., Hoffmann, F., Gasior, K. and Marin, B. (2009), Facts and Figures on Long-Term Care. Europe and North America, Occasional Reports Series 6. Vienna: European Centre.

International Alliance of Carer Organizations. (2018), "Recognizing Carers", available at: http://www.internationalcarers.org/carer-facts/.

International Labour Organisation (ILO), (2017), "Decent work and the 2030 Agenda for sustainable development." https://www.ilo.org/global/topics/sdg-2030/lang--en/index.htm

Karwowski, W. (2005), "Ergonomics and Human Factors: The Paradigms for Science, Engineering, Design, Technology and Management of Human- Compatible Systems", Ergonomics, Vol. 48 No. 5, pp. 436463.

Kehusmaa, S., Autti-Rämö, I., Helenius, H. and Rissanen, P. (2013), "Does informal care reduce public care expenditure on elderly care? Estimates based on Finland's Age Study", BMC Health Services Research, Vol. 13 No. 317, available at:https://doi.org/10.1186/1472-6963-13-317.

KHO. (2005), “The decision of Finnish Supreme Court, 21.1.2005/115 KHO:2005:6”, available at: https://www.finlex.fi/fi/oikeus/kho/vuosikirjat/2005/200500115 (accessed 18 June 2020).

KHO. (2007), “The decision of Finnish Supreme Court 14.11.2007/2900 KHO:2007:79”, available at: https://www.finlex.fi/fi/oikeus/kho/vuosikirjat/2007/200702900 (accessed 18 June 2020).

Kim, K., Kim, J., Voight, A. and Ji, M. (2018), "Listening to the screaming whisper : a voice of mother caregivers of children with autistic spectrum disorder ( ASD )", International Journal of Qualitative Studies on Health and Well-Being, Taylor \& Francis, Vol. 13 No. 1, available at:https://doi.org/10.1080/17482631.2018.1479585.

Law, M., Finkelman, S., Hurley, P., Rosenbaum, P., King, S., King, G. and Hanna, S. (2004), "Participation of children with physical disabilities: Relationship with diagnosis, physical function, and demographic variables", Scandinavian Journal of Occupational Therapy, Vol. 11 No. 4, pp. 156-162.

Leinonen, A. (2011), "Informal family carers and lack of personal time: Descriptions of being outside the sphere of formal help", Nordic Social Work Research, Vol. 1 No. 2, pp. 91-108.

Leitner, A. and Wroblewski, A. (2006). Welfare states and work-life balance, European Societies, 8:2, 295- 


\section{7, DOI: $10.1080 / 14616690600645092$}

Martens, C.T. (2018), "Eldercare policies in Scandinavia between 1993 and 2014: Increased facilitation of family caregiving?", Nordic Journal of Social Research, Vol. 9, pp. 48-67.

Mestheneos, E. and Triantafillou, J. (2005), Supporting Family Carers of Older People in Europe - The PanEuropean Background Report. Empirical Evidence, Policy Trends and Future Perspectives, Munster, Germany: LIT-Verlag.

Ministry of Social Affairs and Health. (2020), "Dependent care allowance", available at: https://valtioneuvosto.fi/artikkeli/-/asset_publisher/1271139/kuntainfo-omaishoidon-tuen-hoitopalkkiotvuonna-2020 (accessed 16 June 2020).

Murphy, N.A., Christian, B., Caplin, D.A. and Young, P.C. (2007), "The health of caregivers for children with disabilities: Caregiver perspectives", Child: Care, Health and Development, Vol. 33 No. 2, pp. 180-187.

Muscara, F., McCarthy, M.C., Thompson, E.J., Heaney, C.M., Hearps, S.J.C., Rayner, M., Burke, K., et al. (2017), "Psychosocial, Demographic, and Illness-Related Factors Associated With Acute Traumatic Stress Responses in Parents of Children With a Serious Illness or Injury", Journal of Traumatic Stress, Vol. 30 No. 3, pp. 237-244.

Official Statistics of Finland (OSF). (2017). Structure of Earnings. Helsinki: Statistics Finland. ISSN=17990092. http://www.stat.fi/til/pra/2017/pra_2017_2018-09-13_tie_001_en.html

Olin, E. and Dunér, A. (2016), "A matter of love and labour? Parents working as personal assistants for their adult disabled children”, Nordic Social Work Research, Vol. 6 No. 1, pp. 38-52.

Overgaard, C. (2019), "Rethinking Volunteering as a Form of Unpaid Work", Nonprofit and Voluntary Sector Quarterly, Vol. 48 No. 1, pp. 128-145.

Raina, P., O’Donnel, M., Rosenbaum, P., Brehaut, J., Walter, S., Russell, D., Swinton, M., et al. (2005), “The Health and Well-Being of Caregivers of Children With Cerebral Palsy", Pediatrics, Vol. 115 No. 6, pp. 626-636.

Reiman, A. and Väyrynen, S. (2018), "Holistic well-being and sustainable organisations - A review and argumentative propositions", International Journal of Sustainable Engineering, Taylor \& Francis, Vol. In press, available at:https://doi.org/10.1080/19397038.2018.1474397.

Schulte, P. and Vainio, H. (2010), "Well-Being at work - Overview and perspective", Scandinavian Journal of Work Environment and Health, Vol. 36 No. 5, pp. 422-429.

Smith, M. and Carayon-Sainfort, P. (1989), "A balance theory of job design for stress reduction", International Journal of Industrial Ergonomics, Vol. 4 No. 1, pp. 67-69.

Smith, A.M. and Grzywacz, J.G. (2014), "Health and well-being in midlife parents of children with special health needs", Families, Systems and Health, Vol. 32 No. 3, pp. 303-312.

Strauss, A. and Corbin, J. (1998), "Basics of Qualitative Research: Techniques and Procedures for Developing Grounded Theory", Thousand Oaks CA, SAGE Publications Inc.

Strickland, B.B., Van Dyck, P.C., Kogan, M.D., Lauver, C., Blumberg, S.J., Bethell, C.D. and Newacheck, P.W. (2011), "Assessing and ensuring a comprehensive system of services for children with special health care needs: A public health approach", American Journal of Public Health, Vol. 101 No. 2, pp. 224-231.

Särkikangas, U. and Autio, M. (2017), "Families with special needs children consuming social and health care services - visible and invisible activities of daily life: Naples Forum on Service 2017 / Working paper", in Evert, G., Cristina, M. and Francesco, P. (Eds.), Proceedings of the 5th Naples Forum on Service: Service Dominant Logic, Network and Systems Theory and Service Science: Integrating Three Perspectives for a New Service Agenda. Sorrento., pp. 1-17.

Thapar, A., Cooper, M. and Rutter, M. (2017), "Neurodevelopmental disorders", The Lancet Psychiatry, Elsevier Ltd, Vol. 4 No. 4, pp. 339-346.

THL. (2020), "Sotkanet.fi Statistics and Indicator Bank, The Finnish Institute for Health and Welfare 20052020", available at: https://sotkanet.fi/sotkanet/en/haku (accessed 16 June 2020).

Verbeek, J.H., Martimo, KP., Karppinen, J., Kuijer, PP., Viikari-Juntura, E. and Takala, EP. (2011), "Manual material handling advice and assistive devices for preventing and treating back pain in workers", Cochrane Database of Systematic Reviews, Vol. 15 No. 6. https://doi.org/10.1002/14651858.CD005958.pub3

Vonneilich, N., Lüdecke, D. and Kofahl, C. (2016), "The impact of care on family and health-related quality of life of parents with chronically ill and disabled children", Disability and Rehabilitation, Vol. 38 No. 8, pp. 761-767. 
Väyrynen, S., Jounila, H., Latva-Ranta, J., Pikkarainen, S. and von Weissenberg, K. (2016), "HSEQ Assessment Procedure for Supplying Network: A Tool for Promoting Sustainability and Safety Culture in SMEs", in Arezes, P. and Rodrigues de Carvalho, P.V. (Eds.), Ergonomics and Human Factors in Safety Management, Boca Raton, FL: CRC, Taylor \& Francis Group, pp. 83-108.

Workers' Compensation Act. (2015), "Workers' Compensation Act 459/2015”, available at: http://www.finlex.fi/en/laki/kaannokset/2015/en20150459 (accessed 2 March 2018).

Yamaoka, Y., Tamiya, N., Izumida, N., Kawamura, A., Takahashi, H. and Noguchi, H. (2016), "The relationship between raising a child with a disability and the mental health of mothers compared to raising a child without disability in japan", SSM - Population Health, Elsevier, Vol. 2, pp. 542-548. 
Table 1. Distribution of ages, employment and type of care by the informal caregivers and the distribution of the ages of the children with special needs

\begin{tabular}{|c|c|c|c|c|c|}
\hline \multicolumn{6}{|c|}{ Age distribution, informal caregiver } \\
\hline & $\begin{array}{l}\text { Below } 34 \text { years } \\
\text { old }(n)\end{array}$ & $\begin{array}{l}\text { From } 34 \text { to } 54 \\
\text { years old }(n)\end{array}$ & $\begin{array}{l}\text { Over } 54 \text { years old } \\
\text { (n) }\end{array}$ & - & - \\
\hline $\begin{array}{l}\text { Informal caregiver } \\
(\mathrm{N}=25)\end{array}$ & 4 & 18 & 3 & - & - \\
\hline \multicolumn{6}{|c|}{ Age distribution, children with special needs } \\
\hline & $\begin{array}{l}\text { Below } 5 \text { years old } \\
\text { (n) }\end{array}$ & $\begin{array}{l}\text { From } 5 \text { to } 9 \text { years } \\
\text { old }(n)\end{array}$ & $\begin{array}{l}\text { From } 10 \text { to } 14 \\
\text { years old }(n)\end{array}$ & $\begin{array}{l}\text { From } 15 \text { to } 19 \\
\text { years old }(n)\end{array}$ & $\begin{array}{l}\text { From } 20 \text { to } 24 \\
\text { years old }(n)\end{array}$ \\
\hline $\begin{array}{l}\text { Children with } \\
\text { special needs } \\
(\mathrm{N}=27)\end{array}$ & 4 & 7 & 10 & 4 & 2 \\
\hline \multicolumn{6}{|c|}{ Employment distribution of informal caregivers } \\
\hline & Employed $(n)$ & Part-time $(n)$ & $\begin{array}{l}\text { Unemployed } \\
\text { (n) }\end{array}$ & - & - \\
\hline $\begin{array}{l}\text { Informal caregiver } \\
(\mathrm{N}=25)\end{array}$ & 8 & 7 & 10 & - & - \\
\hline \multicolumn{6}{|c|}{ Informal care type distribution* } \\
\hline & Physical (n) & $\begin{array}{l}\text { Physical, guidance } \\
\text { (n) }\end{array}$ & $\begin{array}{l}\text { Slightly physical, } \\
\text { guidance }(n)\end{array}$ & Guidance $(n)$ & - \\
\hline $\begin{array}{l}\text { Informal caregiver } \\
(\mathrm{N}=25)\end{array}$ & 8 & 6 & 4 & 7 & - \\
\hline
\end{tabular}

Note. * The physical care type means that the informal caregiver helps the child with personal assistance and the child cannot be of much or any assistance. The physical and guidance care type means that the informal caregiver helps the child with personal assistance, gives guidance and oversees the child's behaviour. The slightly physical and guidance care type means that the informal caregiver gives the child some personal assistance, gives guidance and oversees the child's behaviour. The guidance care type means that the informal caregiver constantly gives guidance and oversees the child's behaviour. 


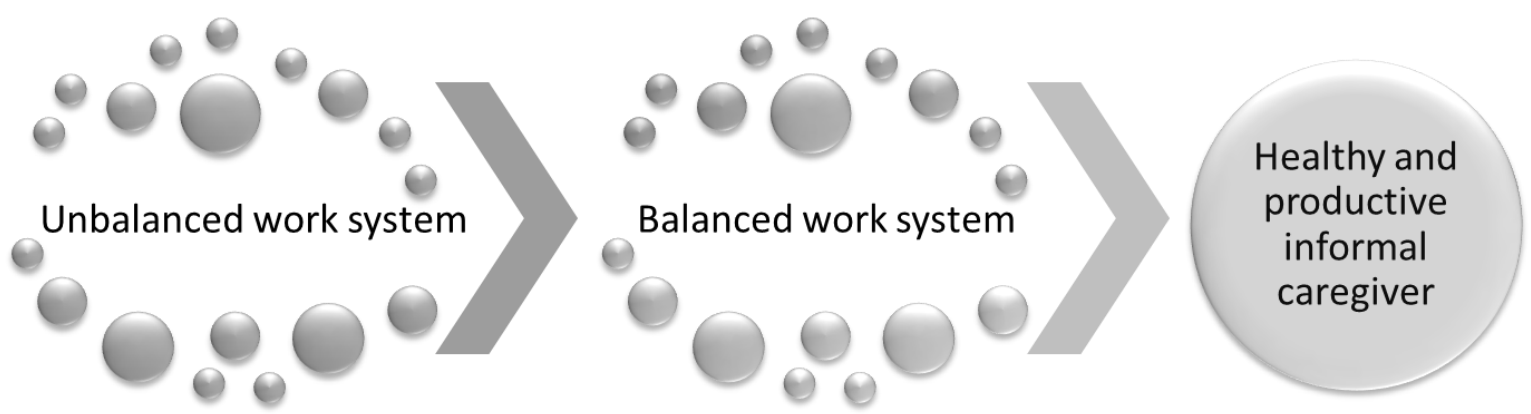

- Challenges identified

- Services and bureaucracy

- Poor financial situations

- Unbalance between informal care and other life

- Informal care tasks

- Worries of/because of child

- Indiscreet behaviour

- Perceived adverse health issues

- Tiredness

- Physical discomfort and pain

- Injuries

- Stress

- Suggestions to balance informal caregiving from the work system perspective

- Transparent organisational support from the municipalities and health and social services

- Clear responsibilities on risk identification and management processes

- Processes that enable work environment and tools and technologies development

- Focused training for informal caregivers and following support to utilise the acquired skills and knowledge in practice

- Focused services depending on the informal care type and situation

- Fluent health service processes for informal caregivers

- Securing adequate dependent care allowance

Figure 1. Unbalanced work system and ideas for balanced work systems regarding informal caregivers 